\title{
Frequency Distributions of Shower Sizes
}

\author{
A. S. Dennis and F. G. Fernald \\ Stanford Research Institute, Menlo Park, Calif.
}

(Manuscript received 3 May 1963, in revised form 10 July 1963)

\begin{abstract}
The number per unit area of radar echoes from isolated showers, as a function of echo radius $r$, is found by analysis of data from several localities to be proportional to $\exp (-\beta \mathrm{r})$, where $\beta$ varies with time and place inversely as the intensity of convective activity. Calculated values of $\beta$ range from $0.8(\mathrm{n} \mathrm{mi})^{-i}$ for intense convection to $1.7(\mathrm{n} \mathrm{mi})^{-1}$ for light shower activity occurring in trade-wind cumuli.
\end{abstract}

\section{Introduction}

Newell (1960) has presented histograms of the diameters, heights and spacings of convective cells based on radar observations. His results suggest that the number of convective cells decreases exponentially both as a function of cell width and as a function of height. This is consistent with the earlier finding of a roughly linear relationship between cell diameter and height; e.g., Byers and Braham (1949), Mather (1949), Donaldson (1958).

Blackmer ${ }^{1}$ has obtained frequency distributions of the length, width and height of cumuliform clouds from aerial photographs. These also approximate an exponential distribution. Cumulonimbus clouds, if present, are invariably outnumbered by towering cumulus, which in turn are outnumbered by small cumulus clouds.

Turning to large convective storms, the data on frequency of occurrence of thunderstorms entered in Fig. 83 of Byers and Braham (1949) yield an exponential distribution when plotted against height. This sample includes storms with tops to $50,000 \mathrm{ft}$.

The above results suggest that convective clouds and the showers within them are distributed systematically with respect to their linear extent over a range exceeding an order of magnitude.

\section{Results of case studies}

The work reported herein forms part of a study of the feasibility of detecting showers and other precipitation forms by a satellite-borne weather radar. ${ }^{2}$ Frequency distributions of radar shower echoes have been ob-

\footnotetext{
${ }^{1}$ Blackmer, R. H., Jr., 1962 : Statistical distribution of cumulus clouds from U-2 photographs. Tech. Report 1, Contract A3(653)3892, Stanford Research Institute, Menlo Park, Calif., 80 pp.

2 Dennis, A. S., 1963: Rainfall determinations by meteorological satellite radar. Final Report, Contract NASr-49(06), Stanford Research Institute, Menlo Park, Calif. 105 pp.
}

tained using PPI photographs from a number of widely separated points.

The first sample studied consisted of 2,429 showers observed on a CPS-9 $(3-\mathrm{cm})$ radar at Eniwetok Atoll between 5 and 12 April 1960. The sample was obtained by counting and measuring at hourly intervals all the isolated showers present between 25 and $75 \mathrm{n} \mathrm{mi}$. Most of the showers were nearly circular and appeared to consist of single cells. Some of the larger ones tended toward an elliptical shape and gave evidence of multicellular structure. They were assigned a radius found by averaging their major and minor axes. Samples obtained in this way include many showers in their growing and dissipating stages. Thus they are not directly comparable to those obtained by following the history of shower echoes and noting the maximum height or diameter attained.

A first inspection of the data indicated that the number of showers in a given radius interval does decrease exponentially with increasing radius. Accordingly, the data were plotted on semi-logarithmic paper (Fig. 1) and fitted by a linear regression of the form

$$
\ln N=\ln N_{0}-\beta r,
$$

where $N$ is the number of showers per given radius interval centered at radius $r, N_{0}$ is the intercept of the regression line on the $N^{\gamma}$ axis, and $-\beta$ is the slope of the regression line.

$\mathrm{Eq}(1)$ is equivalent to

$$
N^{T}=N_{0} \exp (-\beta r) .
$$

For the Eniwetok sample, with $\beta$ expressed in $(\mathrm{n} \mathrm{mi})^{-1}$, $r$ in $\mathrm{n} \mathrm{mi}$, and $N$ given per half-mile radius interval (see Fig. 1),

$$
N=2750 \exp (-1.4 r) .
$$

Upon integration over all values of $r$, this yields for the total number of showers, 3900 , or about 60 per cent 


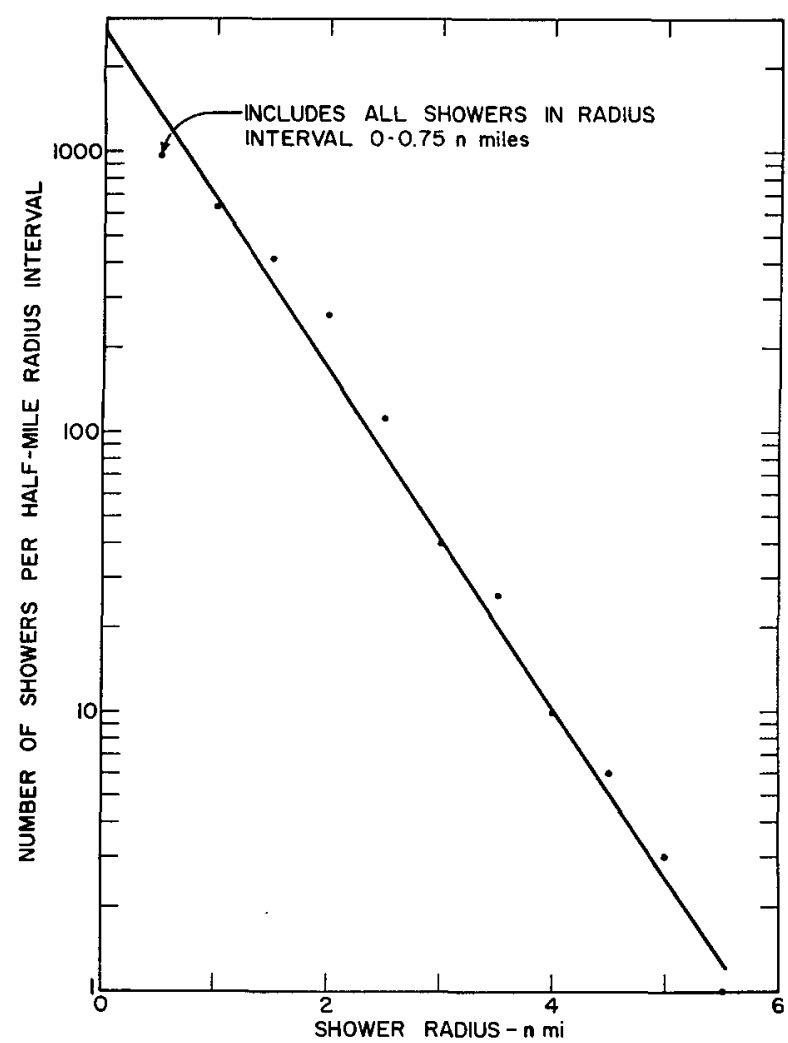

FIG. 1. Frequency distribution of isolated showers as function of radius, Eniwetok, 5-12 April 1960.

more than the original sample contained. It is possible that the exponential distribution breaks down for very small showers, but this is considered unlikely. Fig. 2, based upon Blackmer's (1962) results, shows that the exponential distribution holds for cumulus clouds with lengths down to $0.5 \mathrm{n} \mathrm{mi}$. As the radar echoes within cumulus are somewhat smaller than the clouds themselves, Blackmer's results can be considered applicable to all precipitating cumulus, and to many non-precipitating ones as well.

There are two alternative explanations for the discrepancy between the shower count and the area under the fitted line, namely failure to detect very small showers, and the apparent stretching of those detected because of the finite resolution of the radar system and of the photographic process. As CPS-9 radar sets are very sensitive, frequently detecting virga as well as precipitation reaching the ground, the second explanation appears more reasonable in this case. Agreement between $\mathrm{Eq}$ (3) and the total shower count can be reached by assuming that the apparent radius of each shower was increased approximately $0.3 \mathrm{n} m$ i due to limited resolution.

Similar analyses of isolated showers have been performed using data from radars at Champaign, Ill., and Brize-Norton, England, and on picket ships off the

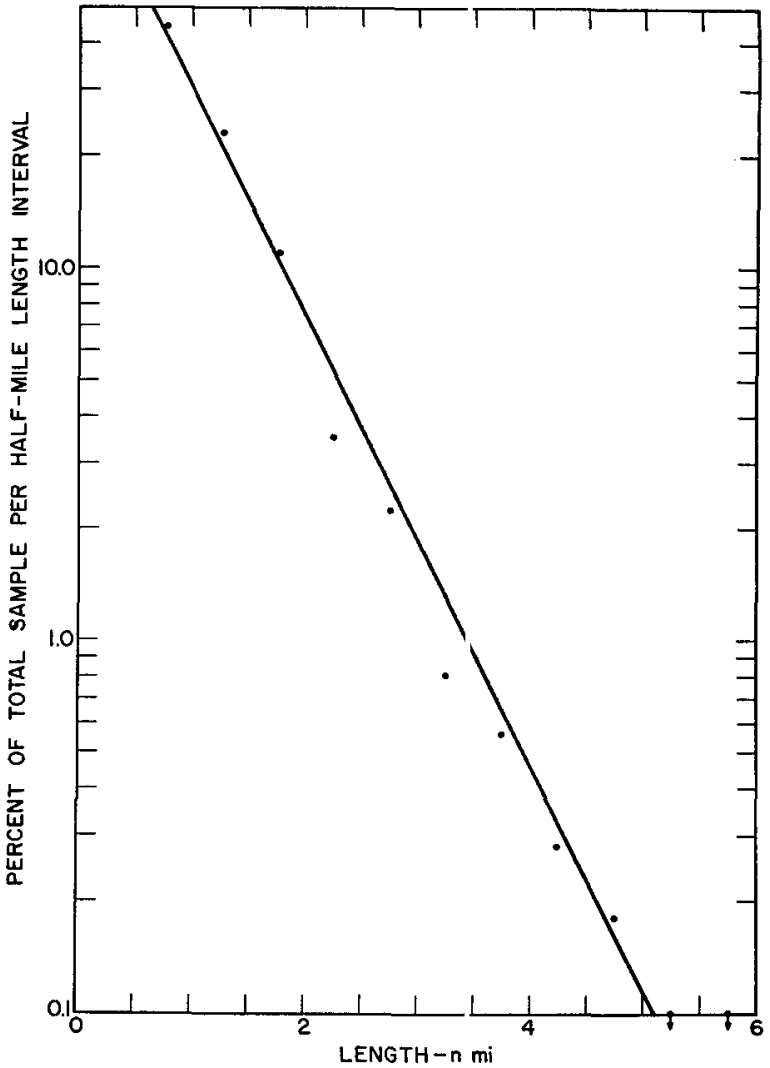

FIG. 2. Frequency distribution of cumuliform clouds as function of length (observed during Florida to ('alifornia flight, 5 August 1960 ; clouds in length interval 0-0.5 $\mathrm{n}$ mi not counted).

west coast of the United States. The available Illinois and English data were limited to the spring months. The picket ship records extendec over a year, though with some gaps. One date to be eximined in each month was chosen at random for each synoptic map time for each picket ship station. The computed value of $\beta$ and the correlation coefficient $(R)$ for zach sample are given in Table 1. (The correlation coeflicients have not been corrected for small sample size.) The closeness of the fit to the exponential distribution is indicated by the high values of $R$. Plots on semi-logar thmic paper, not reproduced here, yielded results cornparable to Fig. 1.

An obvious question at this point is whether the exponential rule holds for instantaneous distributions, or whether it arises from the manner in which some function of the instantaneous distributions, such as the mean shower radius, is distributed in time. Examination of the original data indicates that instantaneous distributions follow the exponential relationship, but that the function $\beta$ varies from day $t_{1}$ ) day as well as with location. The values of $\beta$ reported in Table 1 are thus to be considered as averages over tirne.

Obviously, the function $\beta$ can be determined only for regions large enough to contain statistically significant samples of cumuliform clouds. Cloud and shower 
patterns within such areas must be regarded, from the synoptic-scale viewpoint, as random phenomena. Further study of the variability of $\beta$ with space and time would help determine the degree of resolution required in descriptions of cloud and shower patterns to preserve all information relatable to synoptic-scale events, while excluding local variations.

The combination of a number of samples which follow the exponential law, but with differing values of $\beta$, cannot conform to it exactly. The discrepancies involved in practice are not critical, as shown by the correlation coefficients in Table 1.

Table 1. Fitted values of $\beta$, the size-distribution parameter for isolated showers, and correlation coefficient, $R$.

\begin{tabular}{|c|c|c|c|}
\hline Location & Season or date & $\begin{array}{c}\beta \\
(\mathrm{n} \mathrm{mi})^{-1}\end{array}$ & $R$ \\
\hline Brize Norton, England & Spring & 0.8 & 0.98 \\
\hline Champaign, Illinois & Spring & 1.1 & 0.9 \\
\hline \multicolumn{4}{|l|}{ Picket ship stations } \\
\hline $49 \mathrm{~N}, 131 \mathrm{~W}$ & Entire year & 1.0 & 0.99 \\
\hline $45 \mathrm{~N}, 130 \mathrm{~W}$ & Entire year & $0.9 \& 1.2^{*}$ & 0.99 \\
\hline $40 \mathrm{~N}, 130 \mathrm{~W}$ & Entire year & 1.3 & 1.00 \\
\hline $36 \mathrm{~N}, 128 \mathrm{~W}$ & Entire year & 1.4 & 0.92 \\
\hline $32 \mathrm{~N}, 124 \mathrm{~W}$ & Entire year & 1.4 & 1.00 \\
\hline Eniwetok & 5-12 April 1960 & 1.4 & 0.99 \\
\hline
\end{tabular}

* The first random sample chosen yielded 0.9 , largely because of some very big showers which occurred during March in association with a cold low. A second sample yielded 1.2. The low result for the first sample can be attributed to sampling error, rather than any peculiarity of the location.

\section{Meteorological significance of parameter $\underline{3}$}

The results of Section 2 indicate that the distribution of the radii of isolated showers can be described by a single function $\beta$, which varies with geographic location and with time. Shower distributions containing a relatively high proportion of large showers are described by low values of $\beta$; those containing few large showers by high values of $\beta$.

The close correlation between the radius and height of showers noted above indicates that weather situations with strong convection in deep layers would be characterized by small values of $\beta$, and that convection in shallow layers would be characterized by large values of $\beta$. This is borne out in Table 1 , which shows $\beta$ to be small over land in spring and off the northwestern United States, and large off the California coast and at Eniwetok.

A number of Blackmer's (1962) samples of cloud sizes (in addition to that shown in Fig. 2) have been replotted on semi-logarithmic paper, and the points fitted visually by straight lines. The resulting values of $\beta$ are in the range 1.5 to 1.9 . Thus they overlap the range of values found for the radar data, but extend somewhat higher. This is reasonable, as the radar data, being limited to samples including precipitating clouds, would not include those cases with very large values of $\beta$.

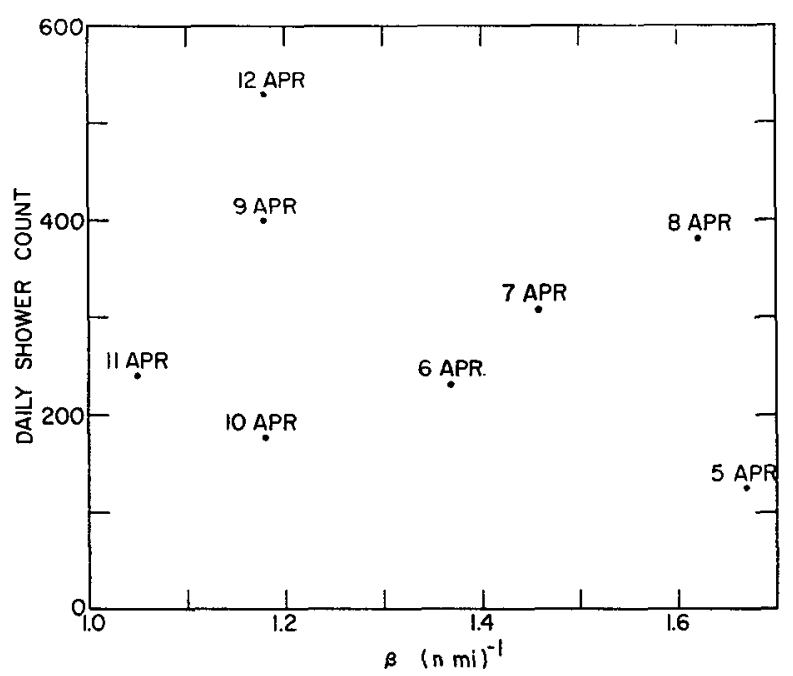

FIG. 3. Total shower count vs. calculated value of $\beta$, by days, Eniwetok, 1960.

As a check on the possibility of a systematic relationship between $\beta$ and the daily shower counts, $\beta$ has been computed for each of the daily shower samples observed at Eniwetok. Fig. 3 is a scatter diagram showing the value found versus the number of showers observed for each day. Inspection of this figure indicates that the two variables are independent. This shows that at least one more parameter, related to shower spacing, is needed to describe shower arrays adequately.

As radiosonde observations are not made at Eniwetok on a routine basis, it is impossible to compare the daily values of $\beta$ and the shower counts with the Showalter Index or other criteria of atmospheric stability. These could include the relative humidity near the surface, wind shear, and low-level convergence or divergence. Studies of tropical showers in the Caribbean area, e.g., Malkus (1952), indicate that the convergence-divergence factor is of major importance.

Acknowledgments. The research reported herein was sponsored by the National Aeronautics and Space Administration under Contract NASr-49(06) with Stanford Research Institute.

\section{REFERENCES}

Byers, H. R., and R. R. Braham, Jr., 1949: The thunderstorm. U. S. Weather Bureau, Washington, D. C., 287 pp.

Donaldson, R. J., Jr., 1958: Analysis of severe convective storms observed by radar. $J$. Meteor., 15, 44-50.

Malkus, J. S., 1952: Recent advances in the study of convective clouds and their interaction with the environment. Tellus, 4, 71-87.

Mather, J. R., 1949: An investigation of the dimensions of precipitation echoes by radar. Bull. Amer. meteor. Soc., 30, 271-277.

Newell, R. E., 1960: Some radar observations of tropospheric cellular convection. Proc. 8th Weather Radar Conf., 315-322. 